\title{
A Quantitative Study of Chromaticism: Changes Observed in Historical Eras and Individual Composers
}

\author{
DANIEL PERTTU \\ The Ohio State University
}

\begin{abstract}
Music historians have observed informally that Western music became increasingly chromatic between roughly 1600 and 1900. This view is tested formally, and the results are shown to be consistent with the standard view. Music historians have similarly assumed that the music of major composers such as Mozart and Beethoven became increasingly chromatic over their respective lifetimes. Measurements of chromaticism in both theme-based and opus-based samples are shown to be inconsistent with these intuitions. At face value, the results of this study affirm that Western art music has become more chromatic over time, but that five major composers' use of chromatic tones changed little (quantitatively) over the course of their careers. Repercussions for stylistic interpretations of these composers are discussed.
\end{abstract}

Submitted 2006 September 12; accepted 2006 September 28.

KEYWORDS: chromaticism, statistics, Bach, Haydn, Mozart, Beethoven, Brahms

\section{INTRODUCTION}

PERHAPS one of the best generalizations one might offer about the history of Western music is that it has exhibited a broad trend toward increased use of chromaticism since about 1600. Few music scholars would disagree with the contention that the music of an early common-practice-period composer such as Monteverdi is less chromatic than that of a late common-practice-period composer such as Mahler. An informal comparison between notated passages from the 17th century and the late 19th century would reveal a greater use of chromatic tones in the latter period.

Not only is it the case that art music in general is presumed to have become more chromatic, but it is tempting to hypothesize that the music of some individual composers appears to show an increase in the use of chromaticism over time. For example, many musicians consider the later works of Beethoven as exhibiting greater chromaticism than his earlier works. Given how widely held this latter view is, there is merit in testing such intuitions empirically.

To this end, three studies are described. In the first study, we look at a large sample of musical themes spanning four centuries of Western instrumental music to determine whether any increase in chromaticism can be detected. In addition, we conduct a second theme-based study to determine whether a comparable increase in chromaticism can be observed in the works of five individual composers, namely Johann Sebastian Bach, Franz Joseph Haydn, Wolfgang Amadeus Mozart, Ludwig van Beethoven and Johannes Brahms. Finally, in our third study, we sample the entire oeuvre of one composer-Mozart. To anticipate the results, we will see that yes, Western instrumental music does broadly exhibit an increase in chromaticism over time. However, with the possible exception of Brahms, the results will be inconsistent with the view that the music of these composers shows any increase in chromaticism over the course of their lives - at least according to the quantitative methods used in this study.

\section{METHOD}

From a practical perspective, it is impossible to test directly the claim that all Western music has become more chromatic over the course of history. The basic terms of this claim must be limited in order to allow 
for a manageable research project. Specifically, we must clarify the meaning of the concept "chromaticism" and we must also restrict the totality of Western music to a reasonable subset or sample.

\section{What is Chromaticism?}

Chromaticism may be defined in different ways. The definition found in The New Grove Dictionary of Music and Musicians provides a standard characterization: "In melodic and harmonic analysis the term 'chromatic' is generally applied to notes marked with accidentals foreign to the scale of the key in which the passage is written" (Dyson \& Drabkin, 2006). Most music theorists would use this as a point of departure for an extended discussion of the importance of chromaticism in relation to musical organization -including both vertical (harmonic) and horizontal (melodic) structure.[1] For the purposes of this study, however, we will simply side-step these more extended ideas and take the New Grove definition at face value. In this study, a note will be operationally considered "chromatic" if its pitch fails to conform to the prevailing key signature.

This definition has a number of potential pitfalls which must be acknowledged at the outset. For example, it is possible that a passage modulates to a different key without a commensurate change of key signature. Consequently, an accidental may render a note consistent with this prevailing (modulated) key yet be construed as "chromatic" in light of the key signature. Another difficulty with this operational definition is that it fails to distinguish "degrees" of chromaticism. For example, a chromatic passing tone might be viewed as less indicative of "chromaticism" than a structural chromatic tone. In this project, we will attempt to identify general trends from a large volume of music. Analyzing each non-scale tone in order to classify it as structural or non-structural would be impractical. Although our operational definition of "chromatic" fails to capture all of the nuances of chromatic theory, it may nevertheless provide a practical index that characterizes the broad trends.

This study consists of three parts. In the first part, we test the general intuition that music has become more chromatic over the common-practice period in Western art music by testing a large sample of themes. That is, we predict that the proportion of "out-of-key" tones will increase over the course of Western common-practice music making. Part of the motivation for this part of the study is to test whether our simple operational definition of chromaticism is sufficient to show a general musical trend. In the second part, we will apply this same methodology to examine the music of individual composers. That is, we will consider whether there is evidence of an increase in chromaticism over the lifetime of specific composers. Because the first two parts tested only themes, we will conduct a third study in which we examine the entire oeuvre of one of these composers, namely Mozart.

\section{Musical Sample}

For the initial study, we choose a pre-existing database consisting of the complete themes from the Barlow and Morgenstern Dictionary of Musical Themes (1948). This dictionary consists of roughly 10,000 musical themes drawn from instrumental Western art music works. These themes themselves reflect Harold Barlow and Sam Morgenstern's intuitions of the principal melodic passages that characterize individual works. For shorter works, the Barlow and Morgenstern collection typically identifies one or two themes. For longer works, many themes are commonly identified. In their Preface, Barlow and Morgenstern suggest that, rather than err on the side of brevity, their collection includes "almost all of the themes the average and even the more erudite listener might want to look up" (p. xi). Little analytic description is provided as to how they selected the passages they did.

As it turns out, the Barlow and Morgenstern collection is structured in a way that reduces the confounding effect of modulation identified earlier. In Western musical practice, it is common for primary themes to be written in the home key of the work as a whole, while secondary themes are often notated in the dominant (or relative major). In their Dictionary of Musical Themes Barlow and Morgenstern fortuitously notate secondary themes in the local (i.e., modulated) key. Consequently, both primary and secondary themes are represented in a key-appropriate context. As a sample source for study, the Barlow and Morgenstern largely sidesteps the problem of modulation.

The Dictionary of Musical Themes does not explicitly include dates of composition. This information was added to the database using established music reference tools. Unfortunately, reference works typically identify the date of publication rather than the date of composition. For posthumously 
published works, the date of publication can be much later than the date of composition. For example, in some cases, first publication did not occur until half a century after the composer's death. In order to avoid these confounds, we elected to eliminate from consideration all themes whose reported "date" was later than the death-date of the composer. It must be acknowledged that this procedure may introduce a bias to the sampled music by under-representing works in the later years of a composer's career.[2]

A related problem with dates is that many dates are specified as a range (such as 1845-1855). A range may be given because the work actually took several years to compose, or because the work was published as part of a collection that was produced over a period of several years, or because scholars are genuinely uncertain of the date of composition. For these works, we operationally defined the "date" of composition as the mid-point in any specified range. Given these conditions, only 5,809 of the 10,000-odd themes available in the Dictionary Musical Themes were used in this study. The average length of the sampled themes is roughly 19.4 notes.

\section{RESULTS}

In examining the relationship between two variables, an appropriate statistical method is to compare the proportion of non-scale tones with the year of composition. Pearson's coefficient of correlation provides a useful summary statistic. Correlation coefficients range between -1 and +1 . A correlation of +1 indicates numerical values that rise and fall in precise synchrony with each other. A correlation of -1 indicates numerical values that rise and fall in complete opposition: a rise in one set of numbers corresponds to a fall in the other set of numbers. A correlation near zero indicates that there is no statistical relationship between the two numerical sets.

The calculation method used in Pearson's correlation coefficient is insensitive to the magnitude of the numerical values, so (for example) it makes no difference whether dates are expressed in years, months, days, or seconds. In the case of scale tones, we predict that as the year of composition increases, the prevalence of scale tones decreases, resulting in a negative correlation. For the 5,809 themes available from the Barlow and Morgenstern collection, the correlation between the reported year of composition and the prevalence of scale tones was found to be $r=-0.155$. While the magnitude of this correlation would seem to be modest, it proves to be statistically significant $(p<0.0000000000000001)$. This means that the probability of observing the relationship between these two variables by chance is less than one chance in a trillion. These results are consistent with the hypothesis that Western music has exhibited greater chromaticism over time.

Rather than expecting an increase in chromaticism with the passing of each successive year, historians would typically think of musical practices in terms of prevailing stylistic periods. This suggests that we reconsider the chromaticism data with respect to historical eras. Identifying the beginning and ending "dates" for a stylistic period is fraught with both conceptual and practical problems. Nevertheless, historians provide conventional dates, such as those shown in Figure 1. Figure 1 reports the percentage of scale tones distributed over four conventionally-defined stylistic periods. As can be seen, the average percentage of scale tones declines with each successive period. Note, however, that there is a negligible difference between the Baroque and Classical periods in the mean percentage of scale tones used in our sample of themes. On the other hand, the difference between the Classical and Romantic periods is statistically significant $(t=6.25 ; p<0.0001)$. 


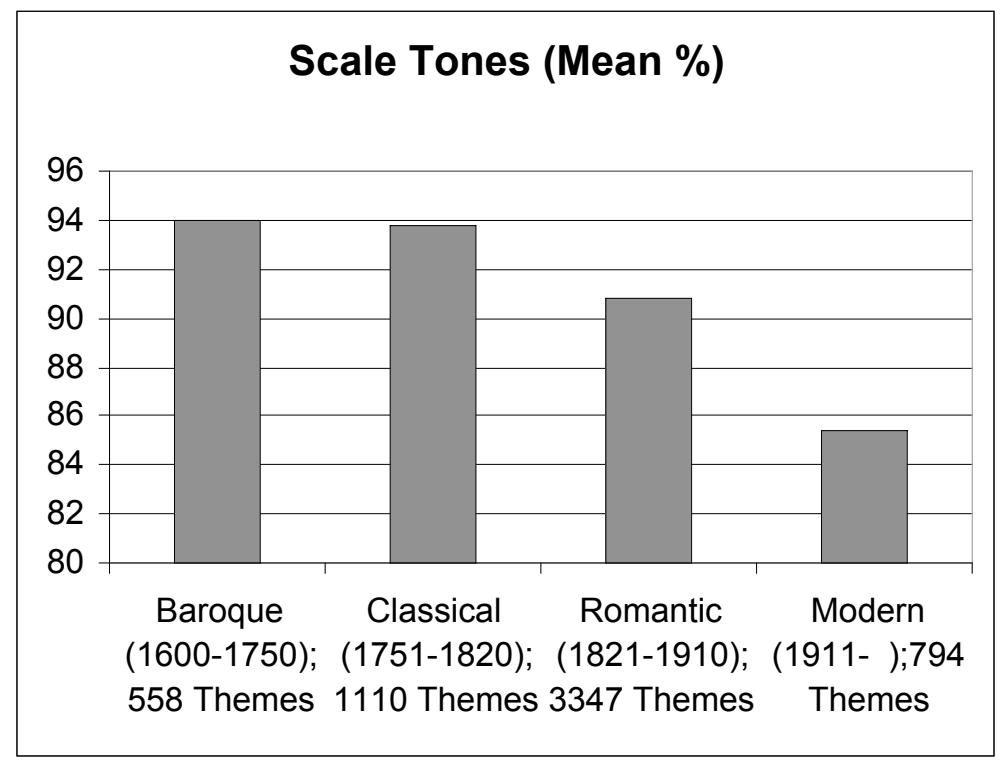

Fig. 1. An illustration of the percent scale tones present in themes from the four historical eras that comprise the common practice period in Western art music. As is expected, the percentage of scale tones decreases over time; i.e., the quantity of chromaticism increases.

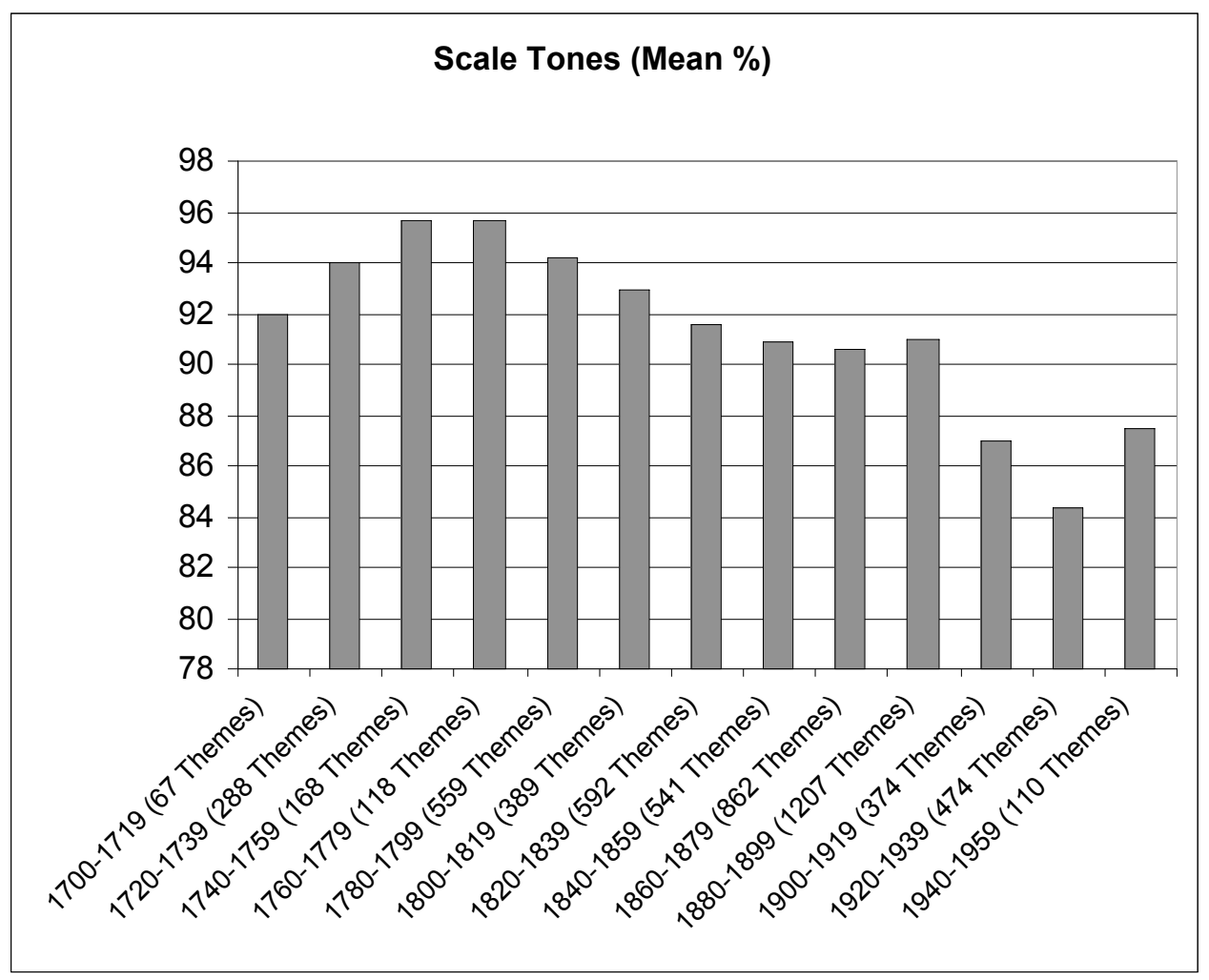

Fig. 2. An illustration of the percent scale tones present in themes in time units partitioned by bidecade.

Once again, the results are consistent with the traditional intuition that Western music became increasingly chromatic over time. Although our operation definition of chromaticism seems limited, it 
nevertheless is able to capture broad trends about composers' use of chromatic tones. One difficulty with looking at particular time periods is that composers who composed in very different styles often lived at the same time. For example, the lives of Haydn and Beethoven overlapped for 39 years. It might be useful, therefore, to focus on the practices of individual composers.

\section{CHANGES IN CHROMATICISM IN INDIVIDUAL COMPOSERS' WORKS}

An important question is whether the works of particular composers exhibit increasing amounts of chromaticism over the course of their careers. In looking at individual composers, statistically generalizable results are possible only with a reasonably large sample of music. Given the small number of notes in each theme, hundreds of themes would be necessary in order to yield reliable results. In the Barlow and Morgenstern database, five composers are well represented: J.S. Bach (267 themes), F.J. Haydn (212 themes), W.A. Mozart (182 themes), L. van Beethoven (551 themes), and J. Brahms (381 themes). Table 1 reports the correlation coefficients between the date of composition and the percent scale tones for the themes from each of these five composers.

Table 1

Correlations between Date of Composition and Percent Scale Tones for Themes by Five Composers

\begin{tabular}{|l|l|l|l|l|}
\hline Composer & $\begin{array}{l}\text { Correlation } \\
\text { Coefficients }(r)\end{array}$ & $\begin{array}{l}\text { Statistical } \\
\text { Significance }(p)\end{array}$ & $\begin{array}{l}\text { Scale Tones } \\
(\text { Mean \%) }\end{array}$ & $\begin{array}{l}\text { Number of } \\
\text { Themes }(n)\end{array}$ \\
\hline Bach & +0.017 & 0.391 & 93.746 & 267 \\
Beethoven & -0.023 & 0.295 & 92.966 & 551 \\
Brahms & -0.050 & 0.165 & 89.38 & 381 \\
Haydn & +0.001 & 0.494 & 94.938 & 212 \\
Mozart & -0.009 & 0.452 & 94.356 & 182 \\
\hline
\end{tabular}

None of the correlations reported in Table 3 reaches statistical significance as conventionally understood. (We might note, however, that there is a 7 in 8 chance that the music of Brahms does exhibit an increase in chromaticism - albeit weak.) With the possible exception of Brahms, we can interpret these results as suggesting that these composers did not tend to use more chromatic tones in themes as their careers progressed. This result is not consistent with prevailing scholarly intuitions, especially regarding the music of Beethoven. Part of the surprise here is that Beethoven is widely regarded as a transitional figure, straddling the classical and romantic periods. His later works, especially the late string quartets, are often viewed as exhibiting a more adventurous or complex character. Since we reported a statistically significant difference between the chromaticism exhibited in the Classical and Romantic periods, one might have expected to see a similar change in Beethoven's music. Apart from broad stylistic periods (such as the Baroque), music scholars often suggest that composers themselves exhibit relatively stable compositional "periods." For example, in the case of Igor Stravinsky, marked changes in his compositions imply three distinct personal stylistic periods. Agreement about such periods is by no means universal. Nevertheless, reference works (such as the New Grove Dictionary of Music and Musicians) will often describe composers by referring to particular periods. It is possible that the apparent lack of chromatic change in Beethoven's music is an artifact of insensitivity to the different stylistic periods. To this end, we can re-analyze the data for individual composers using the compositional "period" information claimed in the New Grove. Figure 3 provides a breakdown for three of the five composers studied, for whom the New Grove describes as having presumed stylistic periods. 


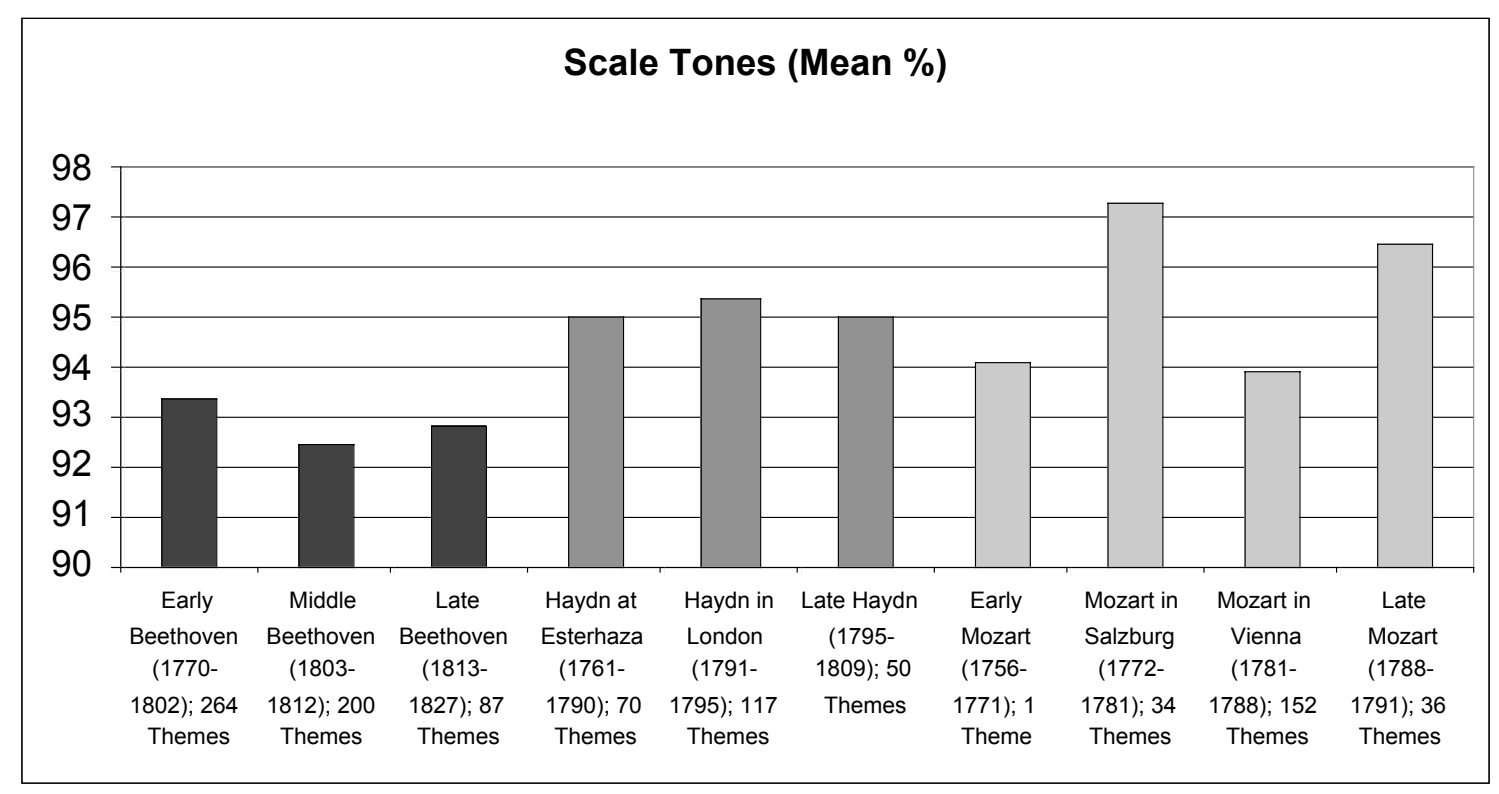

Fig. 3. An illustration of the mean percentage of scale tones for themes by Beethoven, Haydn, and Mozart, broken down by stylistic periods defined by the New Grove Dictionary of Music and Musicians.

Although there are differences in the averages between the three composers, there is no apparent decrease over time for any of them. In the case of Beethoven especially, these results do not appear to conform with commonly held views.

It is important to recall that the results of the first and second studies are based on samples of musical themes. By using themes, our data represent only a single voice and do not include bass and inner voices that may reflect complex harmonic patterns that could be deemed chromatic. It may be the case, for example, that a composer such as Beethoven tends to create predominantly diatonic themes that are nevertheless presented in chromatic harmonic settings. On the other hand, it is possible that themes might exhibit a higher degree of chromaticism (compared to supporting voices) due to the increased presence of non-harmonic tones.

\section{CHROMATICISM IN MOZART'S OEUVRE}

In order to address these potential confounds, a third study was carried out that makes use of a different sampling method. Instead of sampling from selected musical themes, a better approach might involve sampling from the entire corpus of a composer's oeuvre. Obviously, sampling from a composer's entire corpus can be somewhat labor intensive. So, in this third study, we focused on Mozart. A useful operational definition of an "oeuvre" might be all the pieces contained in published collected works excluding instrumental parts, fragments, sketches, works partially attributed to other composers, or arrangements of works by other composers.

In this third study, the sampling goal was to make all of the notes within the composer's oeuvre equally likely to be sampled. This would include both thematic and accompanimental passages, not just themes. In order to secure a reasonable amount of statistical power, it was resolved a priori to sample roughly 1,500 notes. Mozart's oeuvre as we have defined it consists of 18,417 pages of the Neue Mozart Ausgabe (1955-1991), so we selected a single note from every 12th page (approximately 18,417/1,500).

The method of sampling proceeded as follows. Without looking at the notated page, we randomly positioned a stylus on the page, and identified the notehead closest in radial distance to the stylus position. Notes in percussion parts were excluded from the sample since these notes either do not represent precise pitches or only represent tonic and dominant (in the case of timpani). Since the sampling was based on noteheads, tied notes were proportionally more likely to be sampled; for example, a single note onset might be sustained across several measures, and so be notated as a series of $\mathrm{N}$ noteheads. If present, the chromatic inflection of a tied note was maintained. In placing a stylus on a page, it is unlikely that this can 
be done "randomly." In particular, it is likely that there is a mental bias to position the stylus near the middle of the page. In the case of orchestral works, only one system sometimes appears on a single page. This means that placing the stylus near the center of the page might result in a tendency to sample innervoice parts rather than upper- or bass parts. In order to alleviate this tendency, a mental strategy was used in which three successive samples were biased toward the top, middle, and bottom of the page.

Another issue relates to the horizontal positioning of the stylus. The left side of a page is more likely to bias the sample toward sonorities associated with the beginning of a work, and the right side of a page is more likely to bias the sample toward sonorities associated with the end of a work. Also, since pages have blank left and right margins, the left side of the page will tend to favor selecting notes from the beginning of a measure, while the right side of the page will tend to favor selecting notes from the end of a measure. In order to avoid these possible biases, all sampled notes were drawn from near the horizontal middle of the page. In other words, successive samples proceeded from the top center, to the middle center, to the bottom center.

Using this procedure, 1611 notes were sampled from the 18,417 pages of the Neue Mozart Ausgabe that constitute Mozart's oeuvre as we defined it. Each note was characterized as either belonging to, or alien to, the prevailing key. For each sampled note, the nominal date of composition as reported in the Neue Mozart Ausgabe was recorded. When two successive dates were listed, the lesser of the two was chosen. When a larger range of dates was given, an average of the beginning and ending dates was used, with the mean date being rounded up to the next year if needed.

\section{Results}

As in the earlier studies, the dates of composition for each sampled work were correlated with the proportion of scale tones. Once again, a negative correlation would be consistent with an increase in chromaticism over time. Calculating Pearson's correlation coefficient for the 1,611 data points resulted in a positive correlation of $r=+0.012737$ ( $p=0.305$ N.S.). In the first instance, the data are skewed in the opposite direction from what was predicted. Moreover, this result is not statistically significant.

\section{DISCUSSION}

Although our operational definition of chromaticism was able to demonstrate that Western music does indeed increase in chromaticism over time, it showed that the chromaticism present in themes written by five major composers does not appear to increase over the course of their lives. Moreover, the complete oeuvre of Mozart similarly appears to show no increase in chromaticism - at least in terms of quantity. This result implies that the quantity of chromaticism that these individual composers use is a relatively stable stylistic trait. It is possible, however, that the quality of chromaticism in the works of any of these composers does change over the course of their careers. Further empirical research would be needed to address this hypothesis.

In addition, we must acknowledge a marked difference in the results of the theme-based and oeuvre-based samples. The overall percent of scale tones in this sample of Mozart's music was found to be $90.9 \%$, which is notably lower than the comparable percentage of $94.5 \%$ for the Barlow and Morgenstern collection of Mozart themes. This difference implies that musical themes are notably more diatonic than full textures in the case of Mozart. It is unknown whether a similar pattern would be evident for other composers. In light of the differences in sampling for Mozart, it is possible that Bach, Haydn, Beethoven, and Brahms tended to compose themes that remained fairly diatonic throughout their lives, but that the harmonic settings for their works became increasingly chromatic. This hypothesis awaits further empirical research.

\section{AKNOWLEDGMENT}

This research was carried out using the facilities at the Cognitive and Systematic Musicology Laboratory at The Ohio State University. My thanks to Dr. David Huron for his advice and assistance. 


\section{NOTES}

[1] No list of references can do justice to the breadth and depth of writings on the subject of chromaticism. A partial list might include Rameau, 1722; Hindemith, 1942; Mitchell, 1962; Fux, 1966; Forte, 1980; Baker, 1993; and Boatwright, 1994.

[2] In general, composers experience greater renown in their later years and so have little difficulty getting their works published. Often, posthumous publications represent overlooked works from earlier periods of a composer's life that come to light after the composer's death. Consequently, one should not necessarily assume that the elimination of post-death-date publications results in an under-representation of later works.

\section{REFERENCES}

Barlow, H., \& Morgenstern, S. (1948). A Dictionary of Musical Themes. New York: Crown Publishers.

Baker, J. (1993). Chromaticism in Classical Music. In: C. Hatch \& D. W. Bernstein (Eds.), Music Theory and the Exploration of the Past. Chicago: The University of Chicago Press, pp. 233-308.

Boatwright, H. (1994). Chromaticism: Theory and Practice. Fayetteville, NY: Walnut Grove Press.

Dyson, G., \& Drabkin, W. (2006). Chromatic. In: L. Macy (Ed.), Grove Music Online, (accessed Feb. 15, 2006), http://www.grovemusic.com

Eisen, C., \& Sadie, S. (2006). Mozart (3) (Johann Chrysostom) Wolfgang Amadeus Mozart. In: L. Macy (Ed.), Grove Music Online, (accessed Aug. 23, 2006), http://www.grovemusic.com

Forte, A. (1980). Generative chromaticism in Mozart's music. Musical Quarterly, Vol. 66, pp. 459-83.

Fux, J. (1966). Gradus ad Parnassum. A Facsim. of the 1725 Vienna Ed. New York: Broude.

Hindemith, P. (1942). The Craft of Musical Composition. New York: Associated Music Publishers, Inc.

Huron, D. (1995). The Humdrum Toolkit: Reference Manual. Menlo Park, CA: Center for Computer Assisted Research in the Humanities.

Kerman, J., Tyson, A., and Burnham, S. (2006). Beethoven, Ludwig van. In: L. Macy (Ed.), Grove Music Online, (accessed Aug. 23, 2006), http://www.grovemusic.com

Mitchell, W. J. (1962). The study of chromaticism. Journal of Music Theory, Vol. 6, pp. 2-31.

Mozart, W. A. (1955-1991). Neue Ausgabe sämtlicher Werke: in Verbindung mit den Mozartstädten, Augsburg, Salzburg, und Wien / herausgegeben von der Internationalen Stiftung Mozarteum, Salzburg. Kassel, Germany: Bärenreiter.

Rameau, J. (1722). Traité de l'harmonie. Trans. by P. Gossett as Treatise on Harmony. New York: Dover Publications, 1971.

Webster, J. (2006). Haydn, (Franz) Joseph. In: L. Macy (Ed.), Grove Music Online, (accessed Aug. 23, 2006), http://www.grovemusic.com 